\title{
NUMERICAL STUDY ON SEISMIC RETROFIT OF URM WALLS USING TIMBER PANELS
}

\author{
D. Cassol ${ }^{1}$, I. Giongo ${ }^{1}$, and M. Piazza ${ }^{1}$ \\ ${ }^{1}$ University of Trento, Department of Civil, Environmental and Mechanical Engineering \\ via Mesiano 77, 38123, Trento, Italy \\ e-mail: \{davide.cassol-1, ivan.giongo, maurizio.piazza\}@unitn.it
}

\begin{abstract}
Unreinforced masonry (URM) buildings are characterized by high vulnerability to lateral loading, which is often manifested when an earthquake occurs. The present study investigates the effectiveness of a timber-based retrofit solution aimed at reducing the seismic vulnerability of existing URM structures. The retrofit technique consists of connecting timber-based panels, to the interior surface of the walls of a building using mechanical or adhesive pointto-point connections. The application of those panels allows to considerably increase both the in-plane and the out-of-plane capacity of the URM walls, while preserving the original external facades of the retrofitted building. This solution resulted to be relatively fast and easy to install and the reversible nature of the system allows to reduce the impact of the retrofit intervention.

In this work the in-plane behaviour of the retrofitted walls was investigated numerically, building on previous preliminary analyses and in the lights of the results of experimental evidence collected by the authors' research team. The effectiveness of this retrofit solution was analysed on several masonry types, considering different masonry properties and geometries. The influence of various parameters (such as masonry-to panel connection typology, connectors number and position) on the increase of lateral capacity of the retrofitted walls was studied by means of a series of non-linear quasi-static simulations.
\end{abstract}

Keywords: Unreinforced masonry, Seismic retrofit, Seismic rehabilitation, Timber panels. 


\section{INTRODUCTION}

The retrofit solution studied herein aims at reducing the seismic vulnerability of existing masonry buildings while preserving the external facades. The retrofit consists of timber-based panels connected to the interior surfaces of the masonry walls of a building using mechanical or adhesive point to point connections. The use of the timber guarantees fast execution and reversibility of the system. A detailed description of this retrofit solution and the outcomes of numerical simulations were provided by Giongo et al. [1] while the effectiveness of this retrofit technique was experimentally investigated by Giongo et al. [2] via onsite testing of masonry shear walls strengthened with timber panels. Further experimental evidence on walls retrofitted with timber panels and timber-to-masonry connections can be found in Borri et al. [3], Pozza et al. [4], Riccadonna et al. [5] and Rizzi et al. [6].

Other examples of timber based retrofit techniques for masonry structures include the timber strong-backs retrofit solution and the timber frames and sheathing retrofit solution. The timber strong-backs retrofit solution aims to increase the out-of-plane capacity of the URM walls by connecting vertical timber elements to the masonry with mechanical screws or bolts. The effectiveness of this solution was investigated experimentally by Giaretton et al. [7], Dizhur et al. [8] and by Cassol at al. [9]. The timber frames and sheathing retrofit technique is instead a hybrid solution between the strong-backs and the timber panels retrofit techniques with the goal of increasing both the in-plane and the out-of-plane capacity of the URM walls. The effectiveness of this retrofit solution was recently tested by Guerrini et al. [10]. The use of timber panels as retrofit components was also studied for the seismic strengthening of reinforced concrete structures by Sustersic and Dujic [11] [12] and by Smiroldo et al.[13].

In this work the in-plane behaviour of walls retrofitted with cross-laminated timber (CLT) panels was investigated through non-linear quasi-static analysis. Starting from previous numerical analyses reported in [1], different modelling approach and type of analysis were adopted so as to improve the convergence and reach larger deformations. The properties of the connections (panel-to-masonry connections, panel-to-panel connections and anchoring system) were properly calibrated based the results of the aforementioned experimental testing campaigns carried out by the authors. The influence of different parameters on the effectiveness of the retrofit solution was investigated considering the behaviour of single piers, walls with openings and multi-storey walls. An example of retrofitted masonry wall is reported in Figure 1.

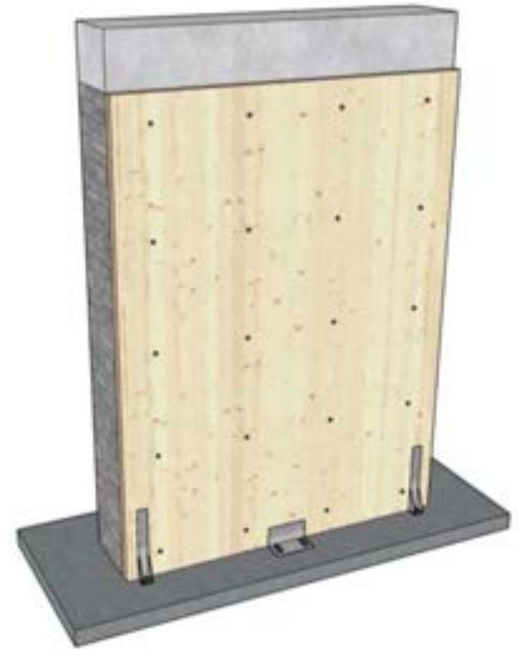

a) Retrofitted masonry wall geometry

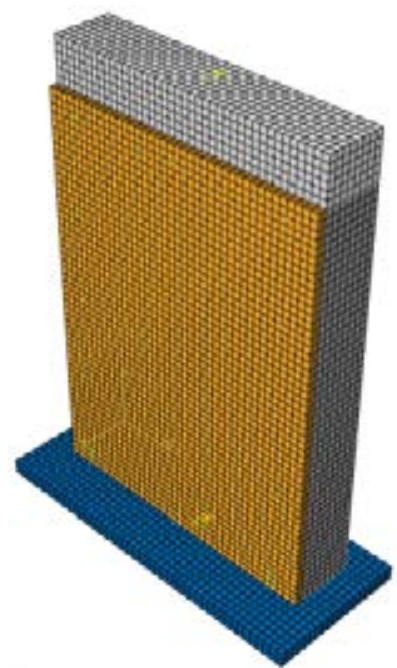

b) Numerical model

Figure 1: Retrofitted masonry wall. 


\section{NUMERICAL MODEL}

The numerical models were realized using the finite element software Abaqus/Explicit [14]. The masonry was modelled as an equivalent, homogeneous and isotropic material. The post cracked behaviour was described with the Concrete Damage Plasticity (CDP) constitutive model. Such model was developed by Lubliner et al. [15] and improved with the modifications proposed by Lee and Fenves [16] and it is suitable to represent the behaviour of quasibrittle materials such as masonry. The adopted yield surface function is a modified version of the Drucker-Prager model, which is governed by a parameter Kc. This parameter represents the ratio of the second stress invariant on the tensile meridian to that on the compressive meridian and it was assumed equal to 0.667 . The dilatation angle, the flow potential eccentricity and the ratio of initial equibiaxial compressive yield stress to initial uniaxial compressive yield stress were assumed equal to $40^{\circ}, 0.1$ and 1.16 respectively, while visco-plastic phenomena were neglected. Parabolic and bilinear stress-strain relations were adopted to describe the compressive and tensile behaviours of the material under axial loading. The maximum values of the stress strain curves correspond to the compressive and tensile strengths while the post cracked behaviours are determined considering the fracture energy in tension and in compression. Such energy values were calculated as recommended by Lourenço [17].

The CLT panel was modelled as a three-layer solid, where the two external layers were defined with the principal direction oriented vertically while the inner layer was oriented horizontally. The timber was implemented as an orthotropic material where inelastic phenomena (such as local crushing at the panel's toe) were approximated using a plastic constitutive model. In this study the timber properties were selected considering timber grade C24 [18]. The point-to-point connections between the CLT panel and the masonry were modelled using one-dimensional connector elements. The properties of such elements were carefully calibrated on the experimental outcomes of different experimental campaigns. Cartesian and Radial thrust connectors were used and the connection between fastener extremities and masonry or timber was ensured by coupling constraints, considering adequate influence radii. Similar approach was adopted also for simulating the presence of anchoring devices such hold-downs (for tension forces) and angle-brackets (for shear forces). A concrete beam and a concrete base were also modelled using an indefinitely elastic and isotropic material with the aim of improving the transfer of the horizontal and the vertical loads to the masonry, and consistently with the load configuration of the experimental tests used as reference for the model validation. The surface-to-surface connections between the masonry and the concrete beam and the base were modelled using the tie constraint (no displacement allowed between coinciding nodes), while the interaction between the other elements was modelled with a hard contact constrain to avoid overlapping of materials.

A regular mesh pattern with eight nodes three dimensional elements (C3D8R) was used. The selected mesh size (i.e. $50 \mathrm{~mm}$ ) is the maximum size that allowed to describe the material response close to the fasteners with adequate accuracy. Dynamic quasi-static analyses were performed to reduce the computational cost of simulations and to improve the convergence. The geometric nonlinearities were considered. The horizontal load was applied in the form of an imposed displacement while the vertical load was simulated as a uniform pressure. The loads were applied slowly (ranging between 0.05 and $0.2 \mathrm{~mm} / \mathrm{s}$ ) and the ratio between the kinetic and the internal energies of the system was monitored to verify the reliability of the analysis.

The model reproducing unreinforced masonry (URM) conditions was validated on the results from cyclic shear-compression testing of double-leaf rubble limestone masonry performed by Gattesco et al [19]. Figure 2 presents the comparison between the experimental 
outcomes [19] and the numerical model employed in this work. It can be observed that the numerical results are consistent with the experimental data in terms of both lateral load $v s$. displacement curve and failure mechanism.

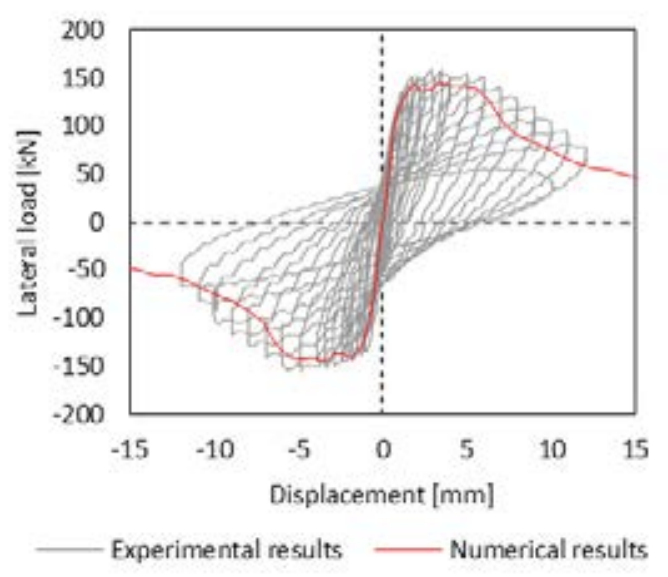

a) Lateral load displacement curves

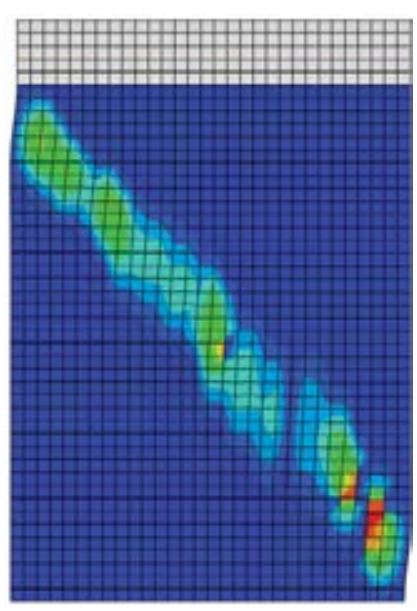

b) Plastic deformation

Figure 2: Model validation by means of a comparison between numerical and experimental results [19].

\section{NUMERICAL ANALYSES}

The effectiveness of the CLT panel retrofit solution was numerically investigated considering masonry piers retrofitted with one or more timber panels, walls with openings and multistorey walls. The behaviour of the retrofitted walls was compared with the response of URM walls and parametric analyses were conducted.

\subsection{Behaviour of retrofitted masonry piers}

The first analyses were developed with the aim of testing the influence of different parameters on the response of the retrofitted walls. Different retrofit configurations were considered by changing the following parameters:

- Masonry properties (M1-M2-M3)

- Masonry thickness (T1-T2-T3)

- Masonry length (L1-L2-L3-L4-L5)

- Masonry overburden (Q1-Q2-Q3-Q4)

- Fastener configuration (C1-C2-C3-C4-C5-C6-C7)

- Connection properties (K1-K2-K3-KR)

- Hold-down properties (HD1-HD2-HD3-HDR)

- Angle bracket properties (AB1-AB2-AB3-ABR)

The mechanical properties of masonry vary widely and are greatly dependent on the properties of its components. Three masonry types were chosen to represent the masonry typologies that can be encountered when retrofitting existing masonry buildings. Table 1 reports the values of the adopted masonry properties. Three different thicknesses were selected with the aim of representing thin, medium and thick walls, see Table 2. All of the tested walls were characterized by the same height $(2700 \mathrm{~mm}$ masonry $+300 \mathrm{~mm}$ concrete beam) while three different lengths were considered, see Table 3 . The analysis was developed in displacement 
control with the vertical load applied uniformly over the concrete beam. Four values of overburden were applied, see Table 4. Two boundary conditions were studied, assuming the wall's ends as either fixed-free (i.e. vertical cantilever) or double fixed. The real behaviour of the top constraint depends on several factors, such as the presence of the bond beam, the features of the lintels and the type of floor-diaphragm. The two selected boundary conditions represent the limit cases of weak and strong spandrels [20]. The combination of the previous properties (masonry properties, masonry thickness, overburden and boundary conditions) resulted in wall models characterized by different failure modes (e.g. rocking and diagonal cracking).

\begin{tabular}{lccc}
\hline Masonry ID & M01 & M02 & M03 \\
\hline Elastic modulus E [MPa] & 600 & 1200 & 1800 \\
\hline Compression strength fc [MPa] & 1.50 & 3.00 & 4.50 \\
\hline Compression fracture energy Gc [N/mm] & 3.98 & 7.50 & 10.58 \\
\hline Tension strength fc [MPa] & 0.050 & 0.075 & 0.100 \\
\hline Tension fracture energy Gt [N/mm] & 0.02 & 0.02 & 0.02 \\
\hline
\end{tabular}

Note: for all the masonry types the density is $18 \mathrm{kN} / \mathrm{m}^{3}$ and the Poisson ratio is 0.25 .

Table 1: Masonry properties.

\begin{tabular}{lccc}
\hline Thickness ID & T1 & T2 & T3 \\
\hline Thickness [mm] & 250 & 400 & 600 \\
\hline
\end{tabular}

Table 2: Masonry thicknesses.

\begin{tabular}{lccccc}
\hline Length ID & L1 & L2 & L3 & L4 & L5 \\
\hline Length [mm] & 1500 & 2000 & 3000 & 4500 & 6000 \\
\hline Length to height ratio [-] & 0.50 & 0.67 & 1.00 & 1.50 & 2.00 \\
\hline
\end{tabular}

Table 3: Masonry lengths.

\begin{tabular}{ccccc}
\hline Overburden ID & Q1 & Q2 & Q3 & Q4 \\
\hline Overburden [MPa] & 0.10 & 0.15 & 0.20 & 0.25 \\
\hline
\end{tabular}

Table 4: Overburdens.

The retrofit solution proposed herein consists of fixing a $60 \mathrm{~mm}$ CLT panel on the surface of the masonry wall. The point-to-point connection between the masonry wall and the timber panel is provided by mechanical or adhesive connections. Different retrofit configurations were analysed by changing the number and the position of the fasteners, see Table 5 . The values of the connection stiffness and shear capacity were selected in accordance with the experimental results obtained in [5] and [6], where experimental testing of dry and adhesive connections under monotonic and cyclic shear loading was performed. The implemented load-displacement curves of the timber to masonry connections are reported in Figure 3a. The connection K1 represents a typical dry connection realised with screw-fasteners [5] and which was used to connect the timber elements (panels or strong-backs) to the wall in the experimental campaigns reported in [2] and [9]. Two adhesive connection types were also considered through $\mathrm{K} 2$ and $\mathrm{K} 3$ curves [6]. Additionally, a rigid connection (KR) was modelled to represent the limit case.

The timber panel was constrained to the ground by two hold-down devices positioned on either side of the timber panel at $100 \mathrm{~mm}$ from the lateral edge and by an angle bracket positioned at the middle of the base of the panel, see Figure 1. Three tensile and shear load dis- 
placement curves were chosen to model the hold-down and the angle bracket connections based on the experimental outcomes presented in [21] and [22], see Figure 3b,c. The cases of rigid tensile and shear connections were also studied (HDR and ABR) to simulate the properties of high-stiffness connections such as the one presented in [23].

\begin{tabular}{lccccccc}
\hline \multicolumn{1}{c}{ Configuration ID } & C1 & C2 & C3 & C4 & C5 & C6 & C7 \\
\hline Connectors number [-] & 12 & 15 & 16 & 20 & 24 & 28 & 35 \\
\hline Horizontal spacing [mm] & 800 & 800 & 533 & 533 & 533 & 533 & 400 \\
\hline Vertical spacing [mm] & 800 & 600 & 800 & 600 & 480 & 400 & 400 \\
\hline Connectors $/ \mathrm{m}^{2}\left[-/ \mathrm{m}^{2}\right]$ & 2.22 & 2.78 & 2.96 & 3.70 & 4.44 & 5.19 & 6.48 \\
\hline
\end{tabular}

Table 5: Connector's configurations.

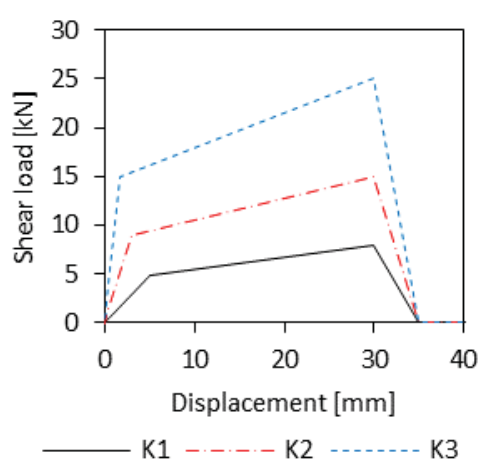

a) Timber panel to masonry connection

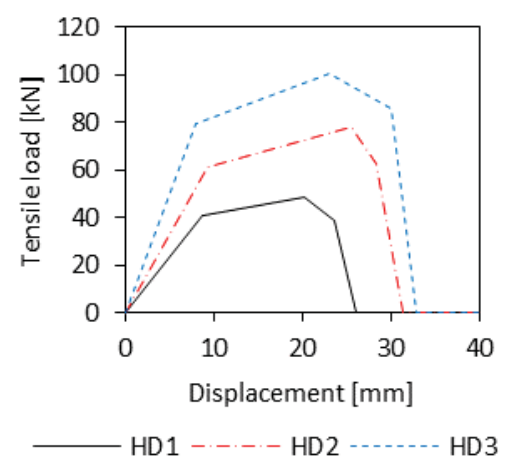

b) Hold-down

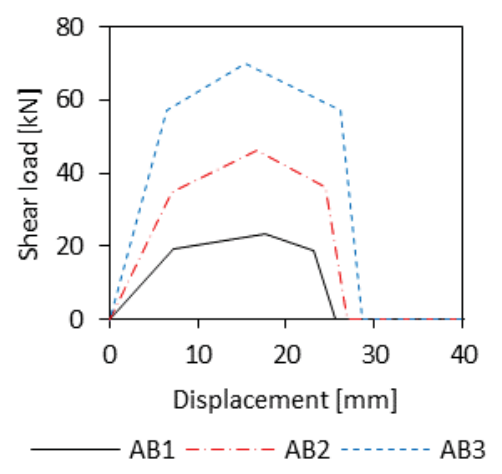

c) Angle-bracket

Note: It was also studied the case of rigid connections (KR, HDR, ABR).

Figure 3: Connection properties.

A base configuration was defined considering the retrofitted masonry wall reported in Figure 1 with the properties M1, T2, L2, Q1, C4, K1, HD2, AB3. Figure 4 presents the results obtained for this configuration in the unreinforced (URM) and retrofitted (R) states for two boundary conditions (fixed-free and double-fixed). It can be observed that in case of shear cracking behaviour (SB) the application of the retrofit allows to increase the lateral and the displacement capacities of the masonry wall considerably. The crack pattern of this model (RSB) is characterized by the formation of a diagonal crack (point 1) followed by a further increase of load bearing capacity. The maximum capacity increase $(56 \%)$ corresponds to the condition where the fasteners' shear capacity is reached. In case of rocking behaviour (RB), the application of the retrofit provides an increase in lateral capacity of $67 \%$. The crack pattern is characterized by the formation of a first horizontal crack (point 2) next to the wall base, typical of the rocking behaviour, followed by the formation of second horizontal crack at midheight of the tension side (point 3) and then, when the maximum lateral capacity is reached, a third crack developed (point 4). The second and the third cracks' formation is due to the tensile stress induced in the masonry by the fasteners. The URM-RB model exhibits a displacement capacity larger than $60 \mathrm{~mm}$ due to the properties of the URM wall. The displacement capacity limit imposed by the Italian code standard [24] is $30 \mathrm{~mm}$ for the URM-RB failure ( $1 \%$ wall's height) and $15 \mathrm{~mm}(0.5 \%$ wall's height) for the URM-SB failure, therefore in this work the behaviour of the masonry walls was studied within the displacement interval from 0 to $60 \mathrm{~mm}$. 


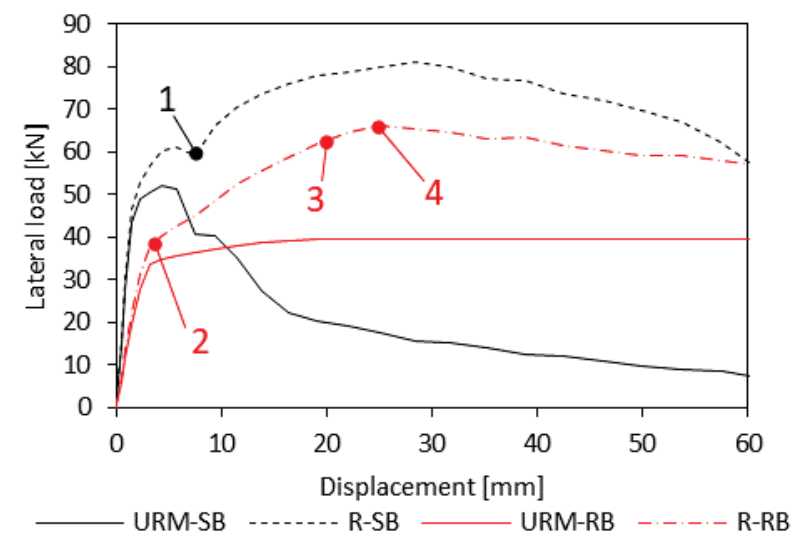

a) Pushover curves

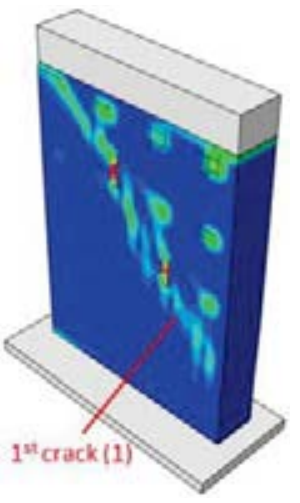

R-SB

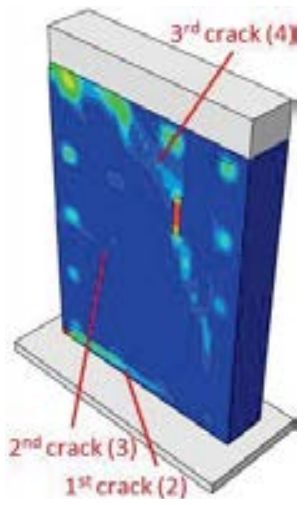

R-RB

b) Crack pattern

Figure 4: Standard configuration results (M1, T2, L2, Q1, C4, K1, HD2, AB3) (unreinforced masonry URM, retrofitted $\mathrm{R}$, shear behaviour $\mathrm{SB}$, rocking behaviour $\mathrm{RB}$ ).

\subsubsection{Timber panel anchoring connection}

Four retrofit configurations were analysed considering different CLT panel anchoring connections: 1) a retrofit solution with no anchoring system to fix the panel to the foundation (CLT); 2) a solution with the connection provided by the sole hold-downs (HD); 3) a solution with just the angle bracket (AB) and 4) a solution with both the hold-downs and the angle bracket $(\mathrm{HD}+\mathrm{AB})$. Figure 5 presents the results for the two boundary conditions. It can be observed that in the first case (double-fixed condition and shear cracking behaviour), the application of the timber panel considerably increases the displacement capacity. As expected, the application of the hold-downs does not affect the performance of the retrofit while the constraint provided by the angle bracket produces a notable increase in the lateral capacity of the URM wall ( $\mathrm{AB}$ and $\mathrm{HD}+\mathrm{AB})$. In the second case (cantilever and rocking behaviour), on the contrary, the hold-downs are of paramount importance in determining the effectiveness of the retrofit.

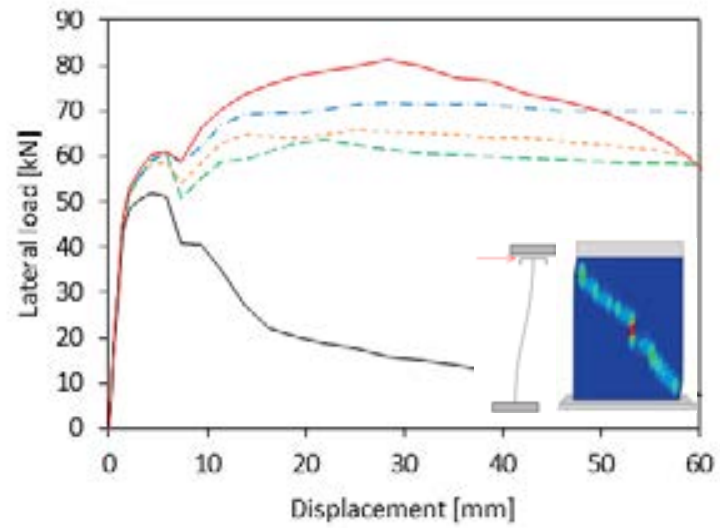

a) Shear behaviour

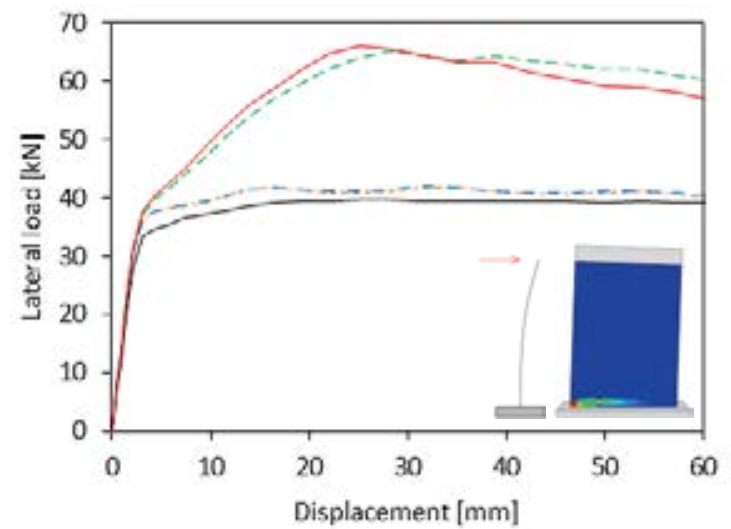

b) Rocking behaviour URM

Figure 5: Effectiveness of the CLT panel to ground connection on the response of the retrofitted wall (base configuration M1, T2, L2, Q1, C4, K1, HD2, AB3).

Additional analyses were performed considering different hold-down and angle bracket properties, see Figure 6 . The effect of the angle bracket properties was investigated considering the shear cracking behaviour (Figure $6 \mathrm{a}$ ) and it was shown that the adoption of stiffer and 
stronger angle brackets (AB3) appreciably increases the maximum capacity. Figure $6 \mathrm{~b}$ shows the effect of different hold-downs on the response of the retrofitted wall in the case of rocking behaviour. The hold-down properties affect the stiffness of the second part of the response curves, when the first horizontal crack is already developed, while the lateral capacity of the retrofitted walls does not change. The shear load on the angle bracket was between 20 and 40 $\mathrm{kN}$ while the tensile load on the hold-downs ranged from 40 to $60 \mathrm{kN}$.

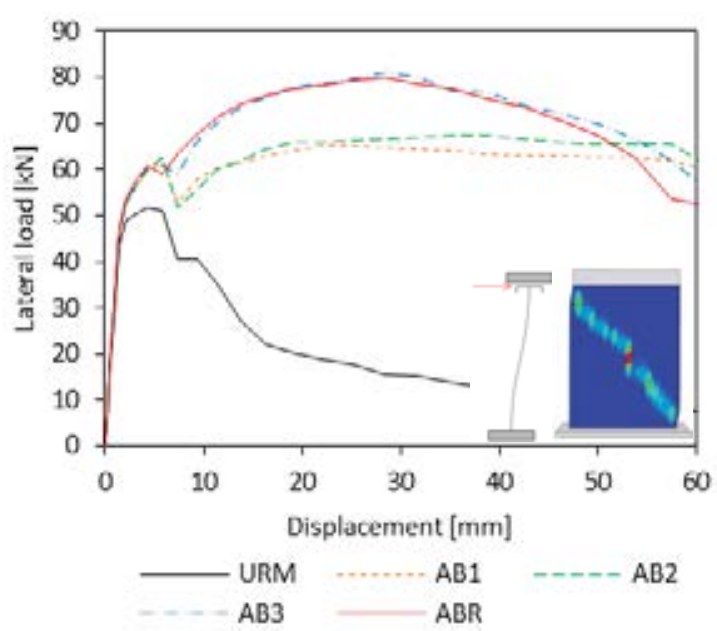

a) Shear behaviour

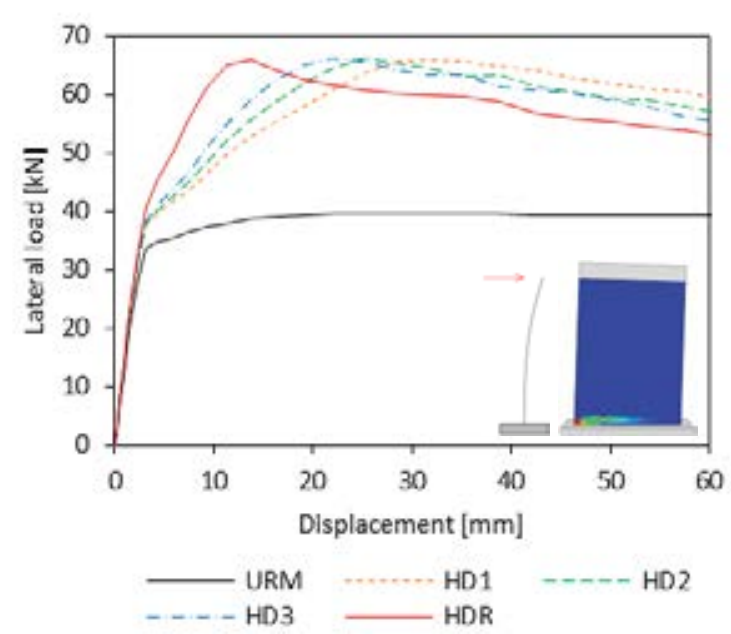

b) Rocking behaviour

Figure 6: Effectiveness of angle bracket (SCB) and the hold-down (RB) properties on the response of the retrofitted wall (base configuration M1, T2, L2, Q1, C1, K1, HD2, AB3).

\subsubsection{Timber panel to masonry wall connection}

Figure 7 reports the behaviour of masonry walls retrofitted considering different types of CLT panel to masonry connections (see Figure 3a). The increase of connection stiffness slightly increases the effectiveness of the retrofit intervention for both failure modes. It can be noticed that in the shear cracking behaviour case, the response of the dry connection K1 presents a small decrease in the load bearing capacity as soon as the wall starts cracking followed then by a strength regain and a further increase. This phenomenon is due to the reduced stiffness of the connection, which requires the wall to displace $10 \mathrm{~mm}$ prior to engaging sufficient fasteners' shear to further increase the global lateral capacity.

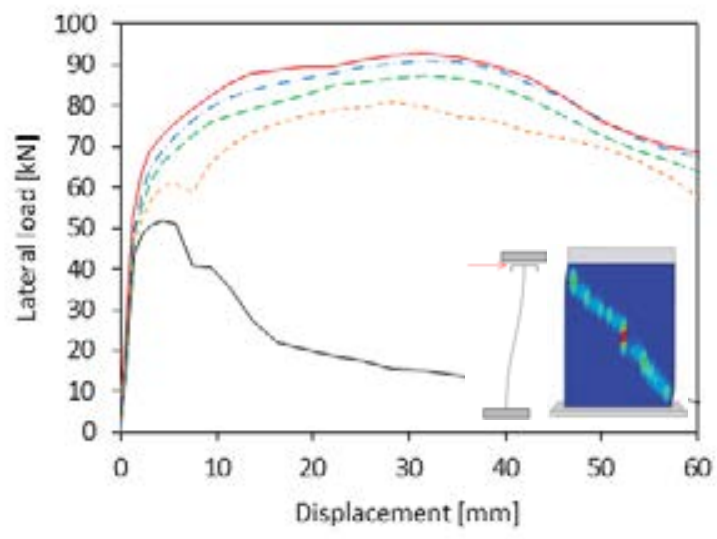

a) Shear behaviour

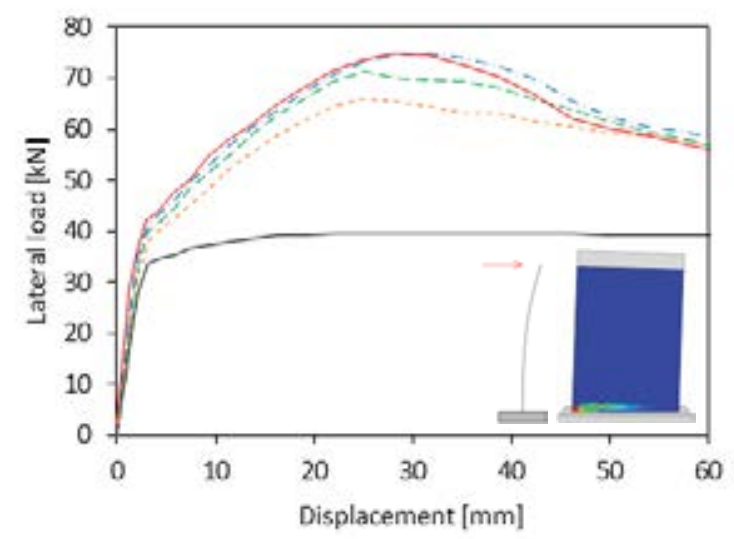

b) Rocking behaviour

Figure 7: Effectiveness of the CLT panel to masonry connection on the response of the retrofitted wall (base configuration M1, T2, L2, Q1, C1, HD2, AB3). 
The influence of the timber-to-masonry connection layout was analysed by varying the number and the position of the point-to-point fasteners, see Figure 8. Not surprisingly, the effectiveness of the retrofit solution grows when increasing the number of connectors, especially for the shear cracking behaviour. It can be observed that the pushover curves obtained from increasing the number of connectors are compatible with those obtained from increasing the fastener stiffness (Figure 7). The inevitable local stress-concentration associated with the stiffer fasteners appeared therefore not to be detrimental to the overall wall performance. As a result, the adoption of fewer fasteners of larger diameter seems a viable option to reduce costs, especially when adhesive fasteners are used.

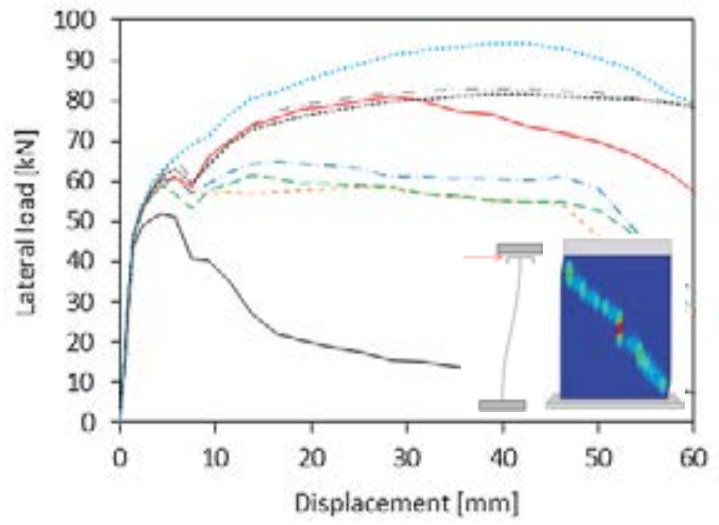

a) Shear behaviour
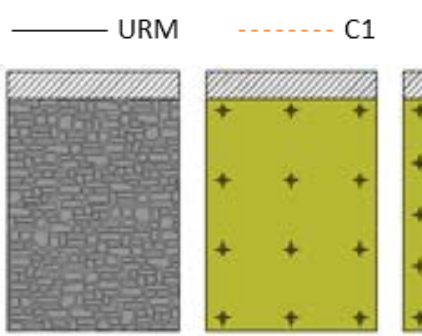

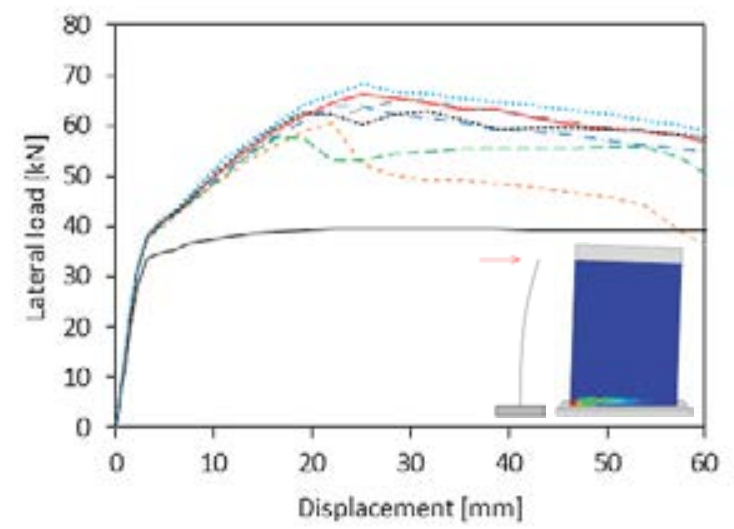

b) Rocking behaviour

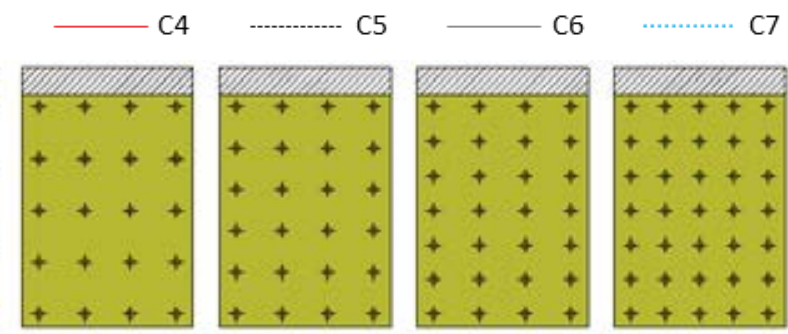

Figure 8: Effectiveness of the connector's configuration on the response of the retrofitted wall (base configuration M1, T2, L2, Q1, K1, HD2, AB3).

\subsubsection{Overburden}

Figure 9 reports the behaviour of retrofitted masonry walls for different overburden levels (see Table 4). As expected, the increase in overburden improves the load bearing capacity of both URM walls and retrofitted walls. Regarding the displacement capacity, when the wall response was governed by rocking (i.e. fixed-free walls), an increase in the vertical loading produced a reduction in the URM wall capacity due to toe crushing (URM-Q3 and URM-Q4). Conversely, when the walls responded in shear (i.e. double fixed-end walls) the displacement capacity was not appreciably affected by the overburden level. As concerns the retrofitted walls, the response appeared not to be influenced by variations in the vertical load independently from the boundary conditions. 


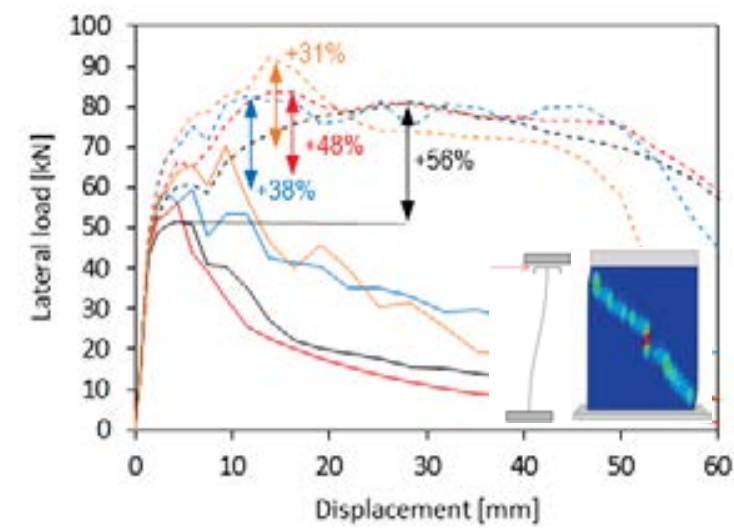

a) Shear behaviour

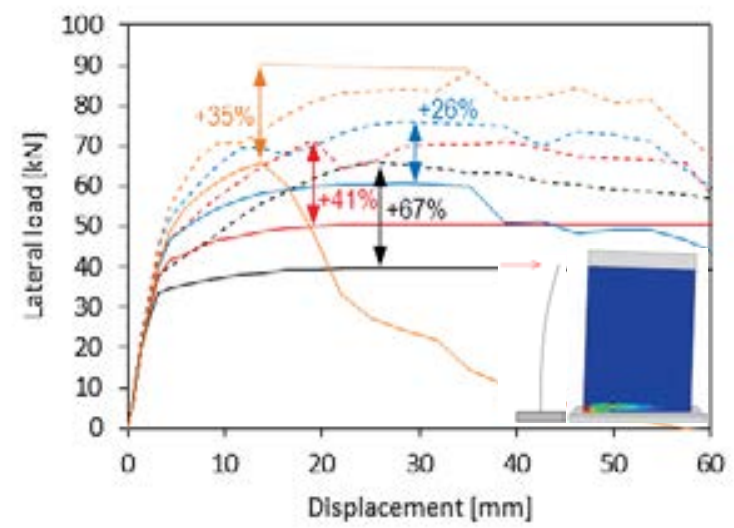

b) Rocking behaviour URM-Q3 -...... R-Q3 URM-Q4 URM-Q3 - R-Q2 URM-Q2

(1)

Figure 9: Effectiveness of the CLT panel retrofit on URM walls characterized by overburdens (base configura-
tion M1, T2, L2, C1, K1, HD2, AB3).

Figure 9: Effectiveness of the CLT panel retrofit on URM walls characterized by overburdens (base configura-
tion M1, T2, L2, C1, K1, HD2, AB3).

\subsubsection{Masonry wall characteristics}

Figure 10 reports the behaviour of retrofitted masonry walls characterized by different masonry properties (see Table 1). It can be noticed that the application of the retrofit solution is effective for all the investigated configurations. Predictably, an increase in the elastic modulus affects the initial slope of the response curves while the improvement of tensile and compressive strength values impacts the behaviour of both the URM and retrofitted walls. The walls URM-M3 and R-M3 are characterized by rocking even in the case of double-fixed conditions. Such response is characterized by the formation of two horizontal cracks, one at the bottom and one at the top of the wall, and the retrofit solution resulted to be effective also in this case. For the RB cases, the effectiveness of the retrofit solution grows when improving the masonry properties. This phenomenon is mainly due to the increase of tensile strength which allows to transfer more load on the masonry wall before that the third diagonal crack occurs (Figure 4).

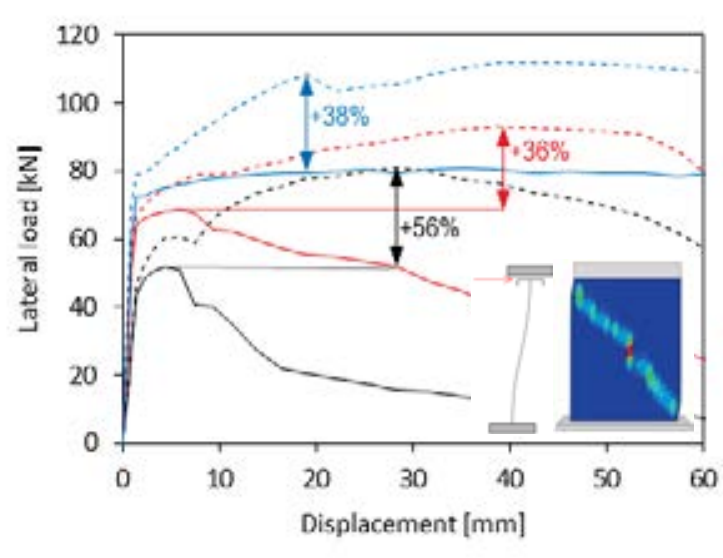

a) Shear behaviour * URM-M2

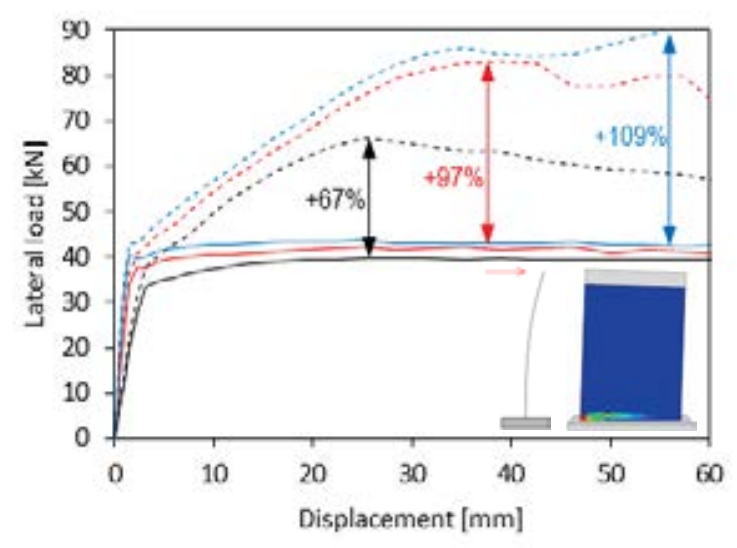

b) Rocking behaviour R-M2 URM-M3 $\mathrm{R}-\mathrm{M} 3$

Note: * walls URM-M3 and R-M3 are characterized by a rocking behaviour for both boundary conditions.

Figure 10: Effectiveness of the CLT panel retrofit solution on URM walls characterized by different masonry properties (base configuration T2, L2, Q1, C1, K1, HD2, AB3). 
Figure 11 reports the behaviour of retrofitted masonry walls characterized by different masonry thicknesses (see Table 2). It can be observed that the application of the retrofit solution considerably increases the shear and the displacement capacities of all the investigated configurations, except for case R-T3 (600 mm thickness) with double-fixed conditions, where the retrofit has an appreciable impact only over the displacement capacity that increases tenfold.

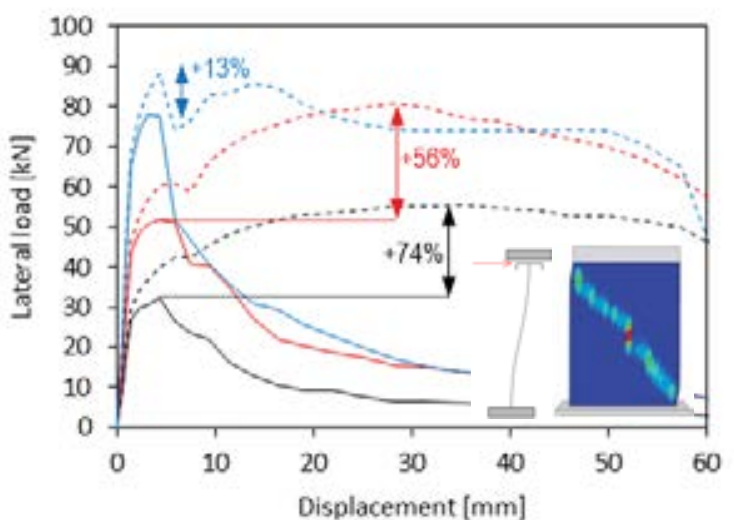

a) Shear behaviour URM-T1 -- R-T1 URM-T2

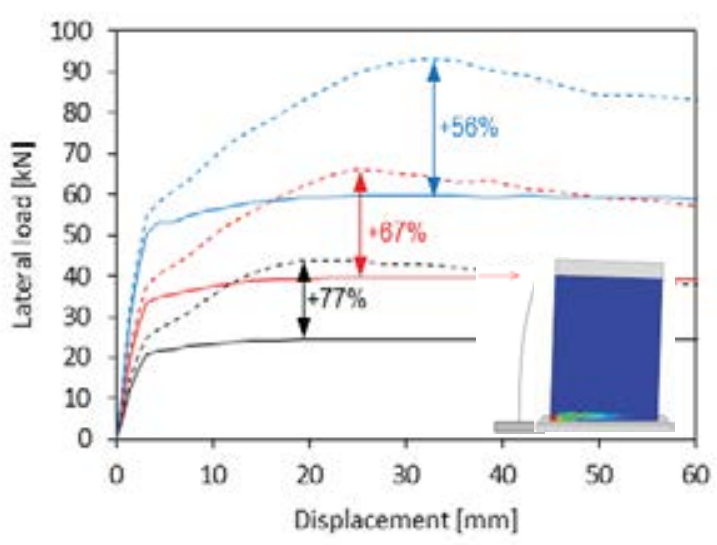

b) Rocking behaviour R-T2 - URM-T3 $\mathrm{R}-\mathrm{T3}$

Figure 11: Effectiveness of the CLT panel retrofit solution on URM walls characterized by different thicknesses (base configuration M1, L2, Q1, C1, K1, HD2, AB3).

Figure 12 shows the behaviour of retrofitted masonry walls characterized by different masonry height to length ratios (see Table 3). The retrofit solution resulted to be effective for all the investigated configurations. As expected, the increase of the length to height ratio reduces displacement capacity of the URM walls in the cantilever condition, but it does not affect the displacement capacity of the retrofitted walls. The shorter walls URM-L1 and R-L1 are characterized by rocking failure independently from the boundary conditions adopted, with the retrofit proving to be effective for both wall configurations. The cases L4 and L5 are described in the following section when considering a multi-panel retrofit.

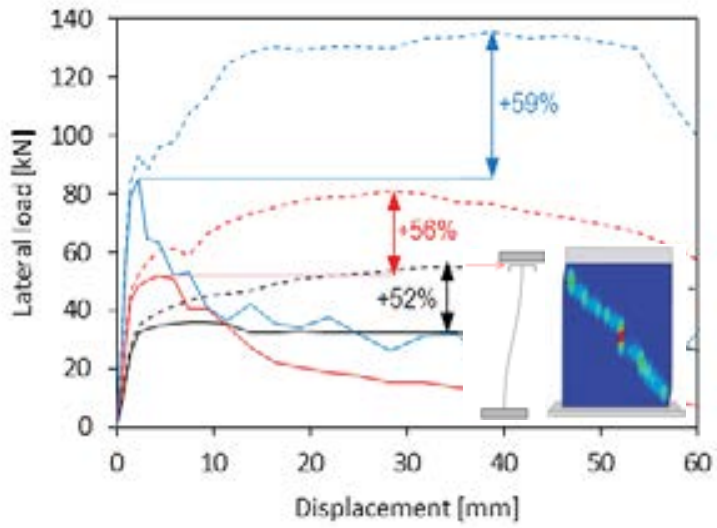

a) Shear behaviour *

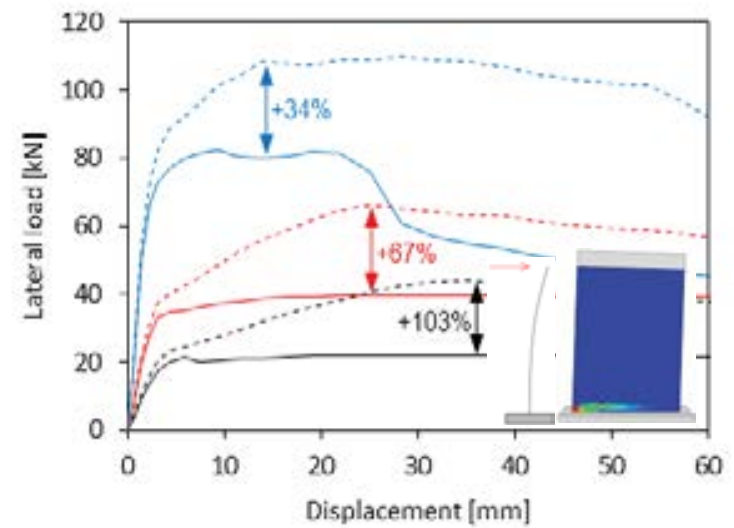

b) Rocking behaviour R-L2 URM-L3 - R-L3

Note: * walls URM-L1 and R-L1 are characterized by a rocking behaviour for both boundary conditions.

Figure 12: Effectiveness of the CLT panel retrofit on URM walls characterized by different aspect-ratios (base configuration M1, T2, Q1, C1, K1, HD2, AB3). 


\subsection{Behaviour of URM walls retrofitted with multiple timber sub-panels}

The dimensions of the CLT panels employed for the wall-retrofit are often subjected to limitation due to transport issue inside the buildings and, consequently, the strengthening of a single wall can be obtained by using two or more "sub-panels" shorter than the wall. In such case, the panel-to-panel connection and the anchoring connections are key aspects in determining the effectiveness of the retrofit solution. The panel-to-panel connection could be achieved by inserting fully threaded timber screws at an angle of $45^{\circ}$ to the joint line (e.g. 8 $\mathrm{mm}$ diameter screws spaced at $200 \mathrm{~mm}$ ). This connection was modelled using onedimensional connector elements calibrated on the experimental outcomes obtained by Hossain et al. [25]. Two panel behaviours were analysed considering different anchoring conditions: the "single panel behaviour" (SPB) (Figure 13a) and the "multi-panel behaviour" (MPB) (Figure 13b). The SPB is characterized by the presence of a hold-down positioned at the two corners of the wall. In such case, the CLT sub-panels behave as a single panel with some interface slip at the panel-to-panel joint due to the screw connection deformability. In the second case (MPB), instead, each sub-panel is anchored at its base with two hold-downs and the CLT panels' response is more similar to that of independent single panels.

Figure 14 and Figure 15 report the pushover curves of a $3000 \mathrm{~mm}$ long URM wall retrofitted with two panels $1500 \mathrm{~mm}$ wide, for the SPB and the MPB. Three panel-to-panel connections were studied: no panel-to-panel connection (J0), panel-to-panel screwed connection [25] (shear stiffness $3000 \mathrm{~N} / \mathrm{mm}$, tension stiffness $3000 \mathrm{~N} / \mathrm{mm}$, shear capacity $6000 \mathrm{~N}$ ) and rigid connection (JR). As visible from the graphs, the adoption of connection J1 resulted in a higher peak capacity if compared to the case with $\mathrm{J} 0$, comparable to the performance obtained with the rigid connection JR. In previous analyses reported in [1], the influence of the panel-topanel connection was found to be less pronounced. It is worth noting that the analyses in the preliminary study reached drift ratios $(\approx 0.2-0.3 \%)$ smaller than those at which the impact of the panel-to-panel connection observed herein became appreciable. The multi-panel solution was then applied to two squat walls, with length to height ratios of 1.5 and 2.0 (L4 and L5), using respectively 3 and 4 CLT panels $1500 \mathrm{~mm}$ wide. The panel retrofit was modelled assuming a SPB which resulted in improvements of the walls' maximum load-bearing capacities larger than $30 \%$. As expected, the squat walls responded mainly in shear with formation of diagonal cracks. As a consequence, rocking was a secondary mechanism, with the tension forces in the "SPB hold-downs" being smaller than $35 \mathrm{kN}$ for all three configurations L3, L4 and L5. The maximum shear force measured in the angle-brackets was also small $(<30 \mathrm{kN})$ because of the increased number of angle-brackets (one for each CLT panel).

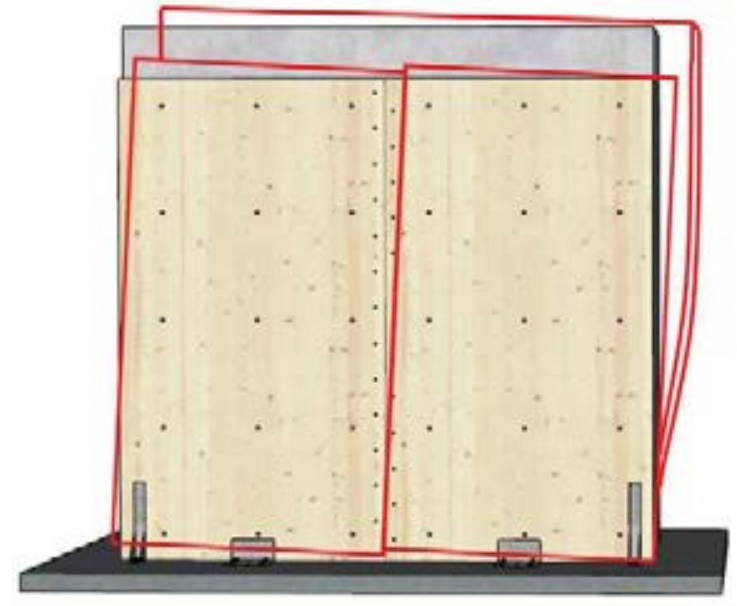

a) Single panel behaviour

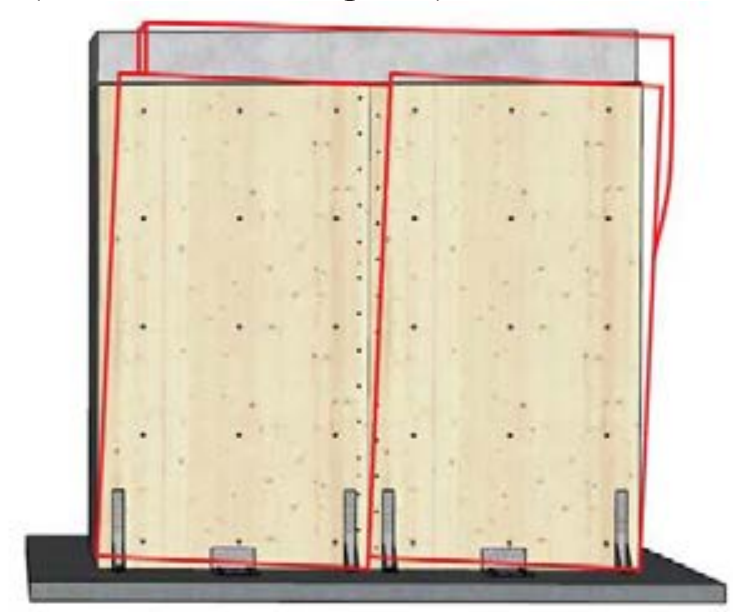

b) Multi-panel behaviour

Figure 13: Multi-panel retrofit solutions. 


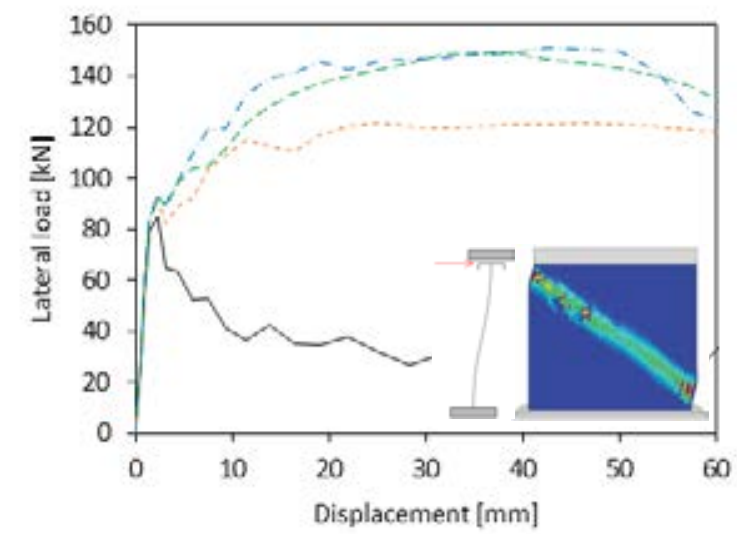

a) Shear behaviour (SPB)

URM -....... J0

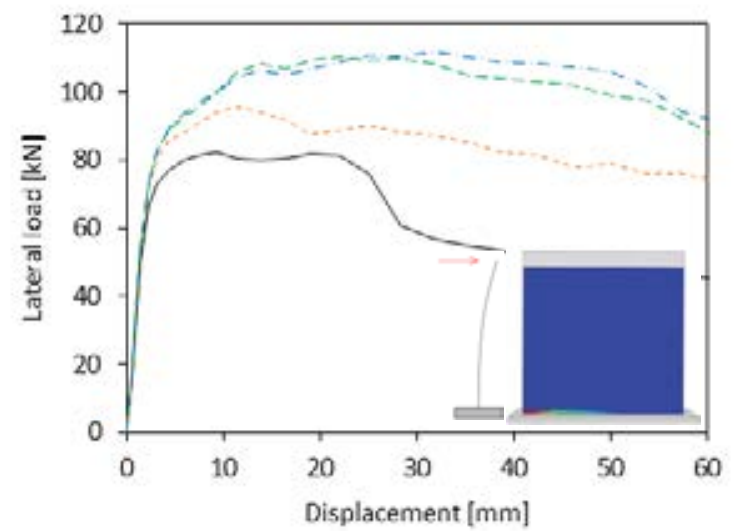

b) Rocking behaviour (SPB)

$-\cdot-\cdot-J R$

Figure 14: Effectiveness of the CLT panel retrofit solution on URM walls, single panel behaviour (SPB) (base configuration M1, T2, L3, Q1, C1, K1, HD2, AB3).

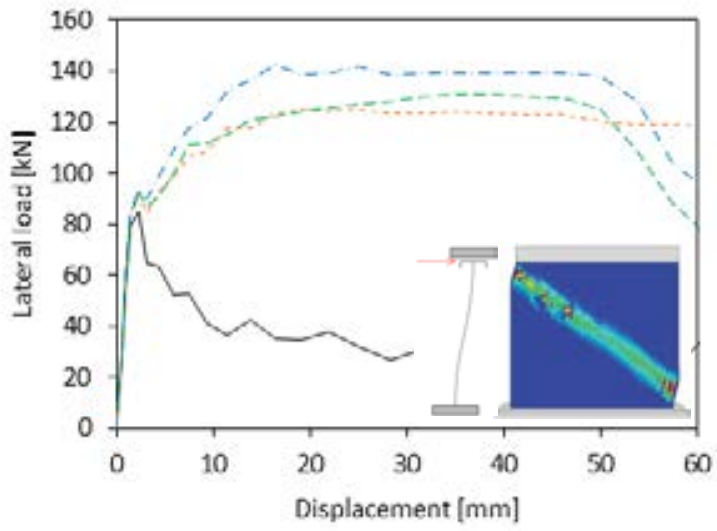

a) Shear behaviour (MPB)

- URM

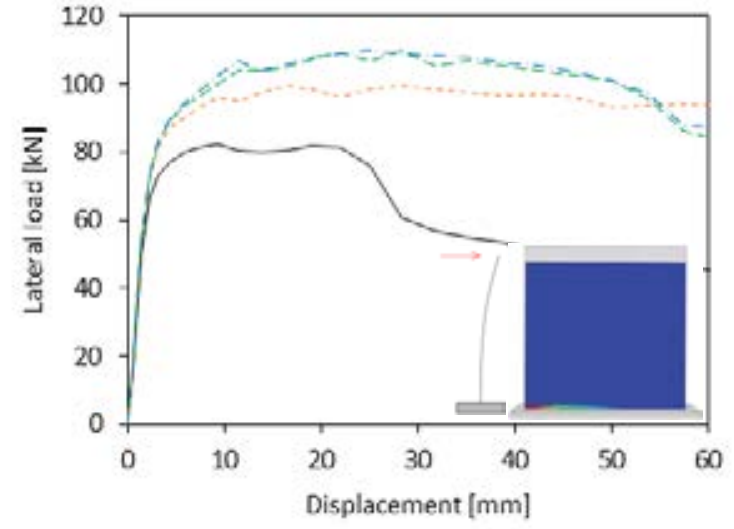

b) Rocking behaviour (MPB)

Figure 15: Effectiveness of the CLT panel retrofit solution on URM walls, multi panel behaviour (MPB) (base configuration M1, T2, L3, Q1, C1, K1, HD2, AB3).

\subsection{Behaviour of retrofitted masonry walls with openings}

The effectiveness of the retrofit when applied to masonry walls with openings was also studied. Two cases were modelled, consisting of two-pier walls with a door opening $\left(900 \times 2100 \mathrm{~mm}^{2}\right)$ or a window opening $\left(900 \times 1000 \mathrm{~mm}^{2}\right.$, sill height $\left.1100 \mathrm{~mm}\right)$. The piers had the same characteristics of those described previously (M1, T2, L2, Q1, C1, K1, HD2, AB3). The spandrel was modelled without any additional tension-resisting element (no lintel nor concrete ring-beam). Figure 16 gives the response curves of the retrofitted walls. Three retrofit conditions were modelled: 1) R1, where the reinforcement was applied only to the masonry piers;2) R2 that sees also the reinforcements of the spandrels, but without any connection between the CLT panels, and 3) R3, where the connection between the CLT panels strengthening the piers and the ones fixed to the spandrels was ensured by inclined timber screws, similarly to what reported in the previous section for the panel-to-panel connection. All three 
retrofit solutions produced a remarkable increase in the shear capacity of the masonry walls (increase $>30 \%$ ) with the contribution of the spandrel retrofit being more effective, expectedly, when the panel-to-panel connection is present.

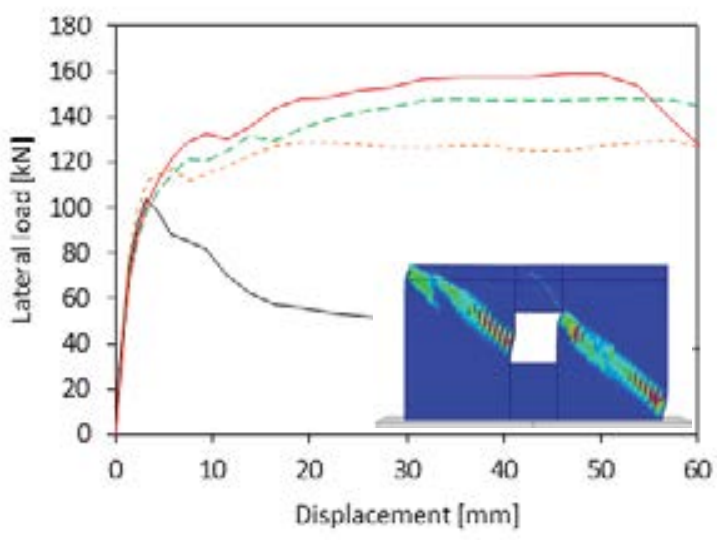

a) Window wall
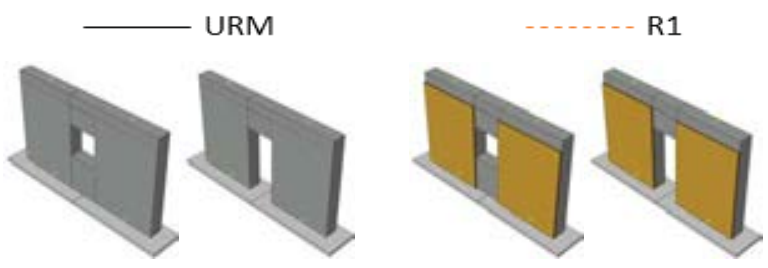

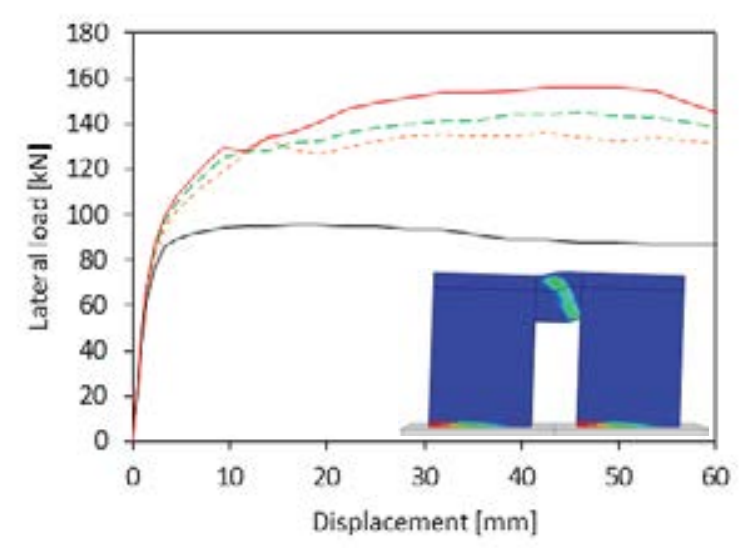

b) Door wall

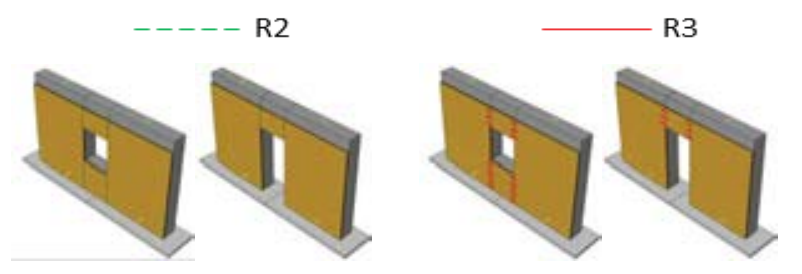

Figure 16: Effectiveness of the CLT panel retrofit solution on URM walls with openings (base configuration M1, T2, Q1, C1, K1, HD2, AB3).

\subsection{Behaviour of two-storey retrofitted masonry walls with openings}

Figure 17 shows the behaviour of two-storey retrofitted masonry walls. The geometry of such walls was derived from the "Door wall" and the "Window wall" analysed in the previous section, respectively for the first and the second level. The horizontal loading was applied at the diaphragm levels assuming a uniform distribution. The three retrofit configurations R1, R2 and R3 previously introduced for the one-storey walls were evaluated also for the twostorey walls. Three inter-storey force transfer mechanisms were analysed: 1) compression only (IS1); 2) compression and tension (IS2); and 3) compression, tension and shear (IS3). The condition IS1 can be obtained by creating slots in the bottom portion of the CLT panels at the second level, so that direct panel-to-panel contact is possible despite the presence of the diaphragm joists (see Figure 17), while the conditions IS2 and IS3 can be achieved by adding steel plates to transfer the tensile and shear forces. The tension and the shear inter-storey anchors were modelled adopting the force displacement curves of HD2 and AB3. The retrofit solution R3-IS3 resulted to be the most effective (increase of lateral load bearing capacity > $70 \%$ ) while the response curves of the other cases provided an increase of lateral capacity larger than $25 \%$. All the retrofit solutions also guaranteed a noticeable increase in the displacement capacity. 


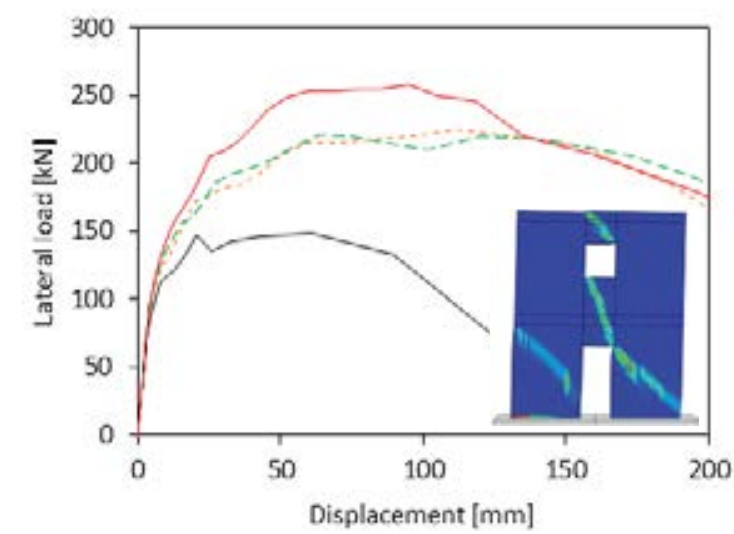

a) Panel-to-panel side connection (IS3)
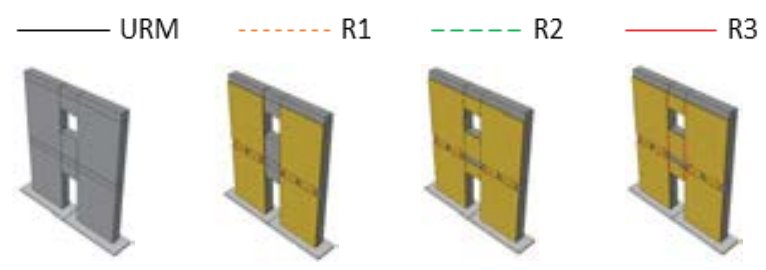

Figure 17: Effectiveness of the CLT panel retrofit solution on two-storey URM walls with openings (base configuration M1, T2, Q1, C1, K1, HD2, AB3).

\section{CONCLUSIONS}

The effectiveness of a timber based retrofit solution where timber panels are connected to the masonry walls through distributed point-to-point connection was numerically investigated. The parametric study addressed several aspects including masonry properties, wall geometry and boundary conditions, and various retrofit configurations. The results obtained herein confirmed and extended the outcomes of a preliminary numerical study previously reported by the authors. The adoption of a quasi-static approach allowed to investigate the behaviour of the retrofitted walls for a wider deformation range and to obtain further information about the lateral load and displacement capacity. The models described herein, benefitted from the outcomes of recent experimental campaigns that were relied to for the calibration of the properties of the connections and that enabled to obtain more refined results. The following conclusions can be drawn:

- The application of the retrofit technique under study can produce a considerable increase in the in-plane strength and displacement capacity of the masonry walls. The timber panel retrofit resulted to be effective for all the studied URM wall configurations characterized by different masonry properties, geometries, stress levels and boundary conditions. The increase in load bearing capacity of masonry walls up to $40 \mathrm{~cm}$ thick, ranged from $\approx 25 \%$ to $\approx 100 \%$. Regarding the displacement capacity, all wall-configurations reached drift values (top displacement/wall height) larger than $1.5 \%$.

- The connection system to anchor the panels to the foundation or to transfer inter-storey forces was confirmed to play a major role in determining the retrofit effectiveness. The best performance was achieved in those configurations where the anchoring/interstorey connection system allowed transferring of compressive, tensile and shear loads (increase of wall shear capacity up to 90\%). Expectedly, the properties of the hold-downs (tension anchors) were most influential when the walls showed a rocking behaviour, while the 
properties of the angle brackets (shear anchors) were most relevant for squat walls with marked shear behaviour. In the case of walls exhibiting diagonal cracking, the timber panel strengthening generated a noticeable increase in the wall displacement capacity even in the absence of any anchoring device.

- An effective timber panel-to-masonry connection can be achieved by installing both dry and adhesive point-to-point fasteners. Fasteners with higher stiffness were found to produce minor yet visible improvements to the intervention effectiveness independently from the wall failure mode. However, the choice of the type of fastener should not prescind from considerations on the masonry type, with adhesive connections being recommended for irregular masonry with thick mortar joints. The parametric study on the fastener numbers and layout showed that 4 connectors per square meter of wall-surface can be considered as sufficient.

- In case of long walls, the application of the timber-based strengthening can be facilitated by installing multiple sub-panels shorter than the wall, without any detriment to the overall effectiveness. In fact, when screwed panel-to-panel connection was provided and when the "timber coating" was anchored at its base by two hold-downs and by an anglebracket for every timber sub-panel the result was consistent with that obtained employing a single CLT panel as long as the masonry wall.

- Predictably, the strengthening of the spandrels can further increase the performance of the retrofit solution $(+50-70 \%$ in wall strength with reference to the configuration where only the piers are strengthened) especially when a spandrel-panel to wall-panel connection is ensured, and when the number of storeys increases and accentuates the spandrel role in coupling the piers.

\section{AKNOWLEDGEMENTS}

The research work was carried out within the framework of the 2019-2021 ReLUIS-DPC network (Italian University Network of Seismic Engineering Laboratories and Italian Civil Protection Agency).

\section{REFERENCES}

[1] I. Giongo, G. Schiro, M. Piazza, On the use of timber-based panels for the seismic retrofit of masonry structures. F. M. Mazzolani, A. Lamas, L. Calado, J. M. Proenca, B. Faggiano eds. In Proceedings of the 3rd International Conference on Protection of Historical Constructions, Lisbon, Portugal, 2017.

[2] I. Giongo, E. Rizzi, D. Riccadonna, M. Piazza Onsite testing of masonry shear walls strengthened with timber panels. Structure and buildings, 2021.

[3] A. Borri, R. Sisti, M. Corradi, Combined Reinforcement of Rubble Stone Walls with CLT Panels and Steel Cords, Structures and Buildings, 2021.

[4] L. Pozza, L. Marchi, D. Trutalli, R. Scotta, In-plane strengthening of masonry buildings with timber panels. Structures and Buildings, 2021. 
[5] D. Riccadonna, I. Giongo, G. Schiro, E. Rizzi, M. A. Parisi, Experimental shear testing of timber-masonry dry connections for the seismic retrofit of unreinforced masonry shear walls. Construction and Building Materials, 52-72, 2019.

[6] E. Rizzi, I. Giongo, D. Riccadonna, M. Piazza, Testing of irregular stone masonry strengthened with cross-laminated timber. Prohitech 2020, 4th International Conference on Protection of Historical Constructions. Athens ,2021.

[7] M. Giaretton, D. Dizhur, J. M. Ingham, Shaking table testing of as-built and retrofitted clay brick urm cavity-walls. Engineering Structures, 70-79, 2016.

[8] D. Dizhur, M. Giaretton, I. Giongo, J. Ingham, Seismic retrofit of masonry walls using timber strong-backs, SESOC Journal, vol. 30, No.2, 2017.

[9] D. Cassol, I. Giongo, J. Ingham, D. Dizhur, Seismic out-of-plane retrofit of URM walls using timber strong-backs. Construction and Building Materials, 2021.

[10] G. Guerrini, N. Damiani, M. Miglietta, F. Graziotti, Cyclic response of masonry piers retrofitted with timber frames and boards. Structures and Buildings, 2021.

[11] I. Sustersic, B. Dujic, Seismic Strengthening of Existing Buildings with Cross Laminated Timber Panels, WCTE, Auckland, New Zealand, 2012.

[12] I. Sustersic, B. Dujic, Seismic shaking table testing of a reinforced concrete frame with masonry infill strengthened with cross laminated timber panels, WCTE, Quebec City, Canada, 2014.

[13] F. Smiroldo, I. Giongo, M. Piazza, Seismic retrofit of masonry infilled frames by using timber panels, In $17^{\text {th }}$ word conference on Earthquake engineering, 17WCEE, Sendai, Japan, 2020.

[14] ABAQUS Computer Software (v.9.12) and user's manual. Simulia, Dassault Systemes.

[15] J. Lubliner, J. Oliver, S. Oller, E. Oñate, A plastic-damage model for concrete. International Journal of Solid and Structures, vol 25, 299-326, 1989.

[16] J. Lee, G. L. Fenves, Plastic-damage model for cyclic loading of concrete structures. Journal of Engineering Mechanics, vol 124, no. 8, 892-900, 1998.

[17] P. Lourenco, Structural masonry analysis: recent developments and prospects, Proceedings of the 15th International brick \& brick masonry conference, Sydney, Australia, 1341-1356, 17-20 February 2008.

[18] UNI EN 338, Structural timber - Strength classes, European Committee for Standardization, Brussels, 2016.

[19] N. Gattesco, C. Amadio, C. Bedon, Experimental and numerical study on the shear behavior of stone masonry walls strengthened with GFRP reinforced mortar coating and steel-cord reinforced repointing, Engineering and Structures, 143-157, 2015.

[20] Applied Technology Council, FEMA 306 Evaluation of earthquake damaged concrete and masonry wall buildings, Federal Emergency Management Agency, 1998.

[21] M. Piazza, T. Sartori, Caratterizzazione meccanica attraverso prove monotone e cicliche dei principali dispositivi di connessione utilizzati negli edifici multipiano in legno. ReLUIS 2015-PR4_Allegato_01-UR_UNITN, 2015. 
[22] I. Gavric, A. Ceccotti, M. Fragicomo, Experimental cyclic tests on cross-laminated timber panels and typical connections, ANIDIS, Bari, 2011.

[23] Smiroldo F., Gaspari A., Viel D., Piazza M., Giongo I.: High performance connections to mitigate seismic damage in cross laminated timber (CLT) structures. In 17th World Conference on Earthquake Engineering, 17WCEE, Sendai, Japan, 2020.

[24] DM 17/01/18. (2008). Norme Tecniche per le Costruzioni - NTC 2008. Ministero delle infrastrutture, Italy, 2018.

[25] A. Hossain; I. Danzig, T. Tannert, Cross-Laminated Timber Shear Connections with Double-Angled Self-Tapping Screw Assemblies, J. Struct. Eng., 2016. 